\title{
The Effects of an Artificial Garden on Heart Rate Variability among Healthy Young Japanese Adults
}

\author{
Hiromi Suenaga *, Kanako Murakami, Nozomi Murata, Syoriki Nishikawa, Masae Tsutsumi \\ and Hiroshi Nogaki (D)
}

Graduate School of Medicine, Faculty of Health Sciences, Yamaguchi University, Yamaguchi 753-8511, Japan; sunflower333@outlook.jp (K.M.); nzm_r_k4@icloud.com (N.M.); b010up@yamaguchi-u.ac.jp (S.N.); tutumi@yamaguchi-u.ac.jp (M.T.); nogaki@yamaguchi-u.ac.jp (H.N.)

* Correspondence: hiro1204@yamaguchi-u.ac.jp

Received: 23 October 2020; Accepted: 14 December 2020; Published: 17 December 2020

\begin{abstract}
Spending time in nature might positively influence mental health by inducing a relaxed state. Recently, gardens have been created on hospital rooftops in Japan to help inpatients recover from various physical and mental aliments. However, there is little evidence regarding any positive physiological effects of artificial gardens designed for health. The purpose of this study was to assess the psychological and cardiovascular responses incited by artificial natural environments. Japanese university students $(n=38)$ participated in a one-group pretest post-test experiment conducted at the Yamaguchi Flower Expo in Japan in October 2018, designed to assess whether exposure to four environments (forest, flowers, ocean, and artificial garden for health) influenced heart rate variability measures. After pretesting to determine baseline measurements, participants completed a circuit through the four natural environments. Following circuit completion, post-testing determined that the low frequency/high frequency ratio was significantly lower in the overall sample and the four areas had similar influences on heart rate variability. Findings suggest that exposure to nature by walking through natural areas and in rooftop artificial gardens might enhance the balance between the sympathetic and parasympathetic nervous systems.
\end{abstract}

Keywords: heart rate variability; artificial gardens; physiological effects; sympathetic nervous system; parasympathetic nervous system; nature environments

\section{Introduction}

Mental health problems, such as depression, are common and pose serious health problems. According to the 2004 World Health Organization's World Mental Health Surveys, the prevalence of mental health problems in the United States was high in (26.4\%) [1]. In urban or stressful societies, some psychological problems are increasingly influencing health [2-7]. Some studies have found mental health benefits associated with contact with nature [8], and the stress-reducing influence of visiting public parks is well established [9]. Recent experimental research has confirmed those effects [10], and large-scale epidemiological studies, particularly on green space and health, reported that forest bathing or forest therapy improved physical and mental health because of the forest aspect of the experience [11-14]. Previous studies on mental health and occupational health found that images of nature, such as forests [15], oceans [16], or flowers [17,18] promoted relaxation. Apparently, forests' therapeutic effects are caused by the forest environment's activation of parasympathetic nervous activity and improvement of immune function resulting from the inhalation of D-limonene and $\alpha$-pinene, which are major components of forest environments [19]. Just looking at pictures or videos of forests has enhanced physiological [20] and psychological [21] relaxation. Many studies have examined the relationships between green space, including forests and gardens, 
and health, but only a few studies have been conducted on blue spaces (visible surface waters, i.e., lakes, rivers, and oceans), and due to methodological heterogeneity, the association with health remains unclear [22-24]. In addition, physical activity in a natural environment has been reported to benefit mental health compared to indoor physical activity [25]. Other similar studies have also demonstrated that short-term exposure, like a 15 min walk in green space, could have health benefits $[26,27]$. To apply these findings, some modern Japanese hospitals have built rooftop gardens that resemble natural greenery so that inpatients can relax and recover. However, there is little research on the psychological and physical effects of artificial gardens on inpatient health. In addition, the differences in the influences of different types of nature, such as forest, flower, and the ocean, on individual health are unclear.

Therefore, this study investigated whether an artificial garden designed for health influenced health in ways similar other types of nature. Data were objectively obtained by continuously recording the heartrate variability (HRV) of a sample of 38 Japanese university students while they walked through four human-created environments (forest, flower, ocean, and Garden for Health).

\section{Materials and Methods}

\subsection{Participants}

Twenty-five female and 13 male Japanese university students (Age $\mathrm{M}=21.7, \mathrm{SD}=1.1$ ) were recruited to participate in this study. Emails were sent and posters were displayed on campus to attract students to participate. The inclusion criteria were: (1) non-smoker; (2) not pregnant; (3) no history of cardiac disease (e.g., arrhythmia); (4) not currently taking medication for hypertension, depression, anxiety, or sleep; and (5) ability to walk for $30 \mathrm{~min}$ without a break. All the participants were fully informed about the study's purposes and procedures. By signing the consent form, they agreed to participate in the study.

This study was conducted in accordance with the Declaration of Helsinki, and the Ethics Committees of the Center for Environment, Yamaguchi University Graduate School of Medicine, Japan (project identification no. 548), approved its protocol.

\subsection{Design and Procedure}

\subsubsection{Study Site}

This study was conducted at the Yamaguchi Flower Expo in Japan in October 2018. Four areas of the expo were used to gather the participants' HRV data: (1) 3.6 ha planted forest, (2) 3.6 ha planted flower area, (3) 3.9 ha ocean area, and (4) 043 ha Garden for Health (Figures 1 and 2). The Japan Landscaping Association and Yamaguchi University Hospital conducted these exhibitions for health promotion.

\subsubsection{Preliminary Survey}

The preliminary survey was conducted a week before the participants were exposed to the treatment (the walk through the four areas of the study site). They were asked about three physical conditions that might be associated with their participation: allergic rhinitis, sleep disorder, and regular exercise habits. Allergic rhinitis was added to the questionnaire due to concerns that walks in the flower or forest areas might result in allergic rhinitis. At the same time, the participants underwent evaluation of autonomic nervous functions as baseline $\mathrm{HRV}$ in the sitting position using the Fatigue Measurement Device VM302 (Hitachi Systems Co. Ltd., Tokyo, Japan) in the university laboratory.

The VM302 evaluates autonomic nervous function by monitoring HRV in 90 s electrocardiogram (ECG) interval data, which are transmitted to an external computer. 


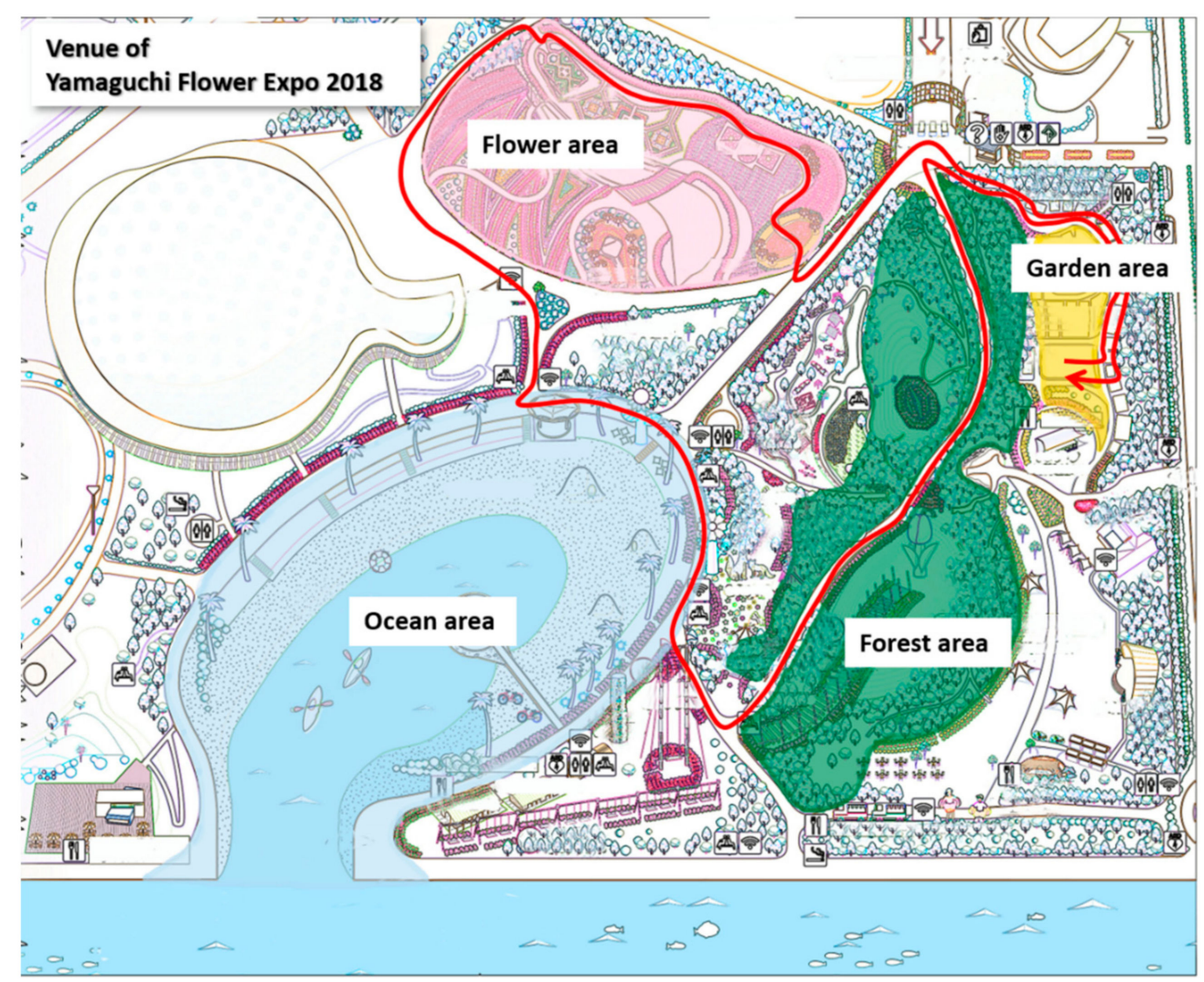

Figure 1. Study site: flower area (pink), ocean area (blue), forest area (green), and Garden for Health (yellow). The red trails indicate the main walking circuit.

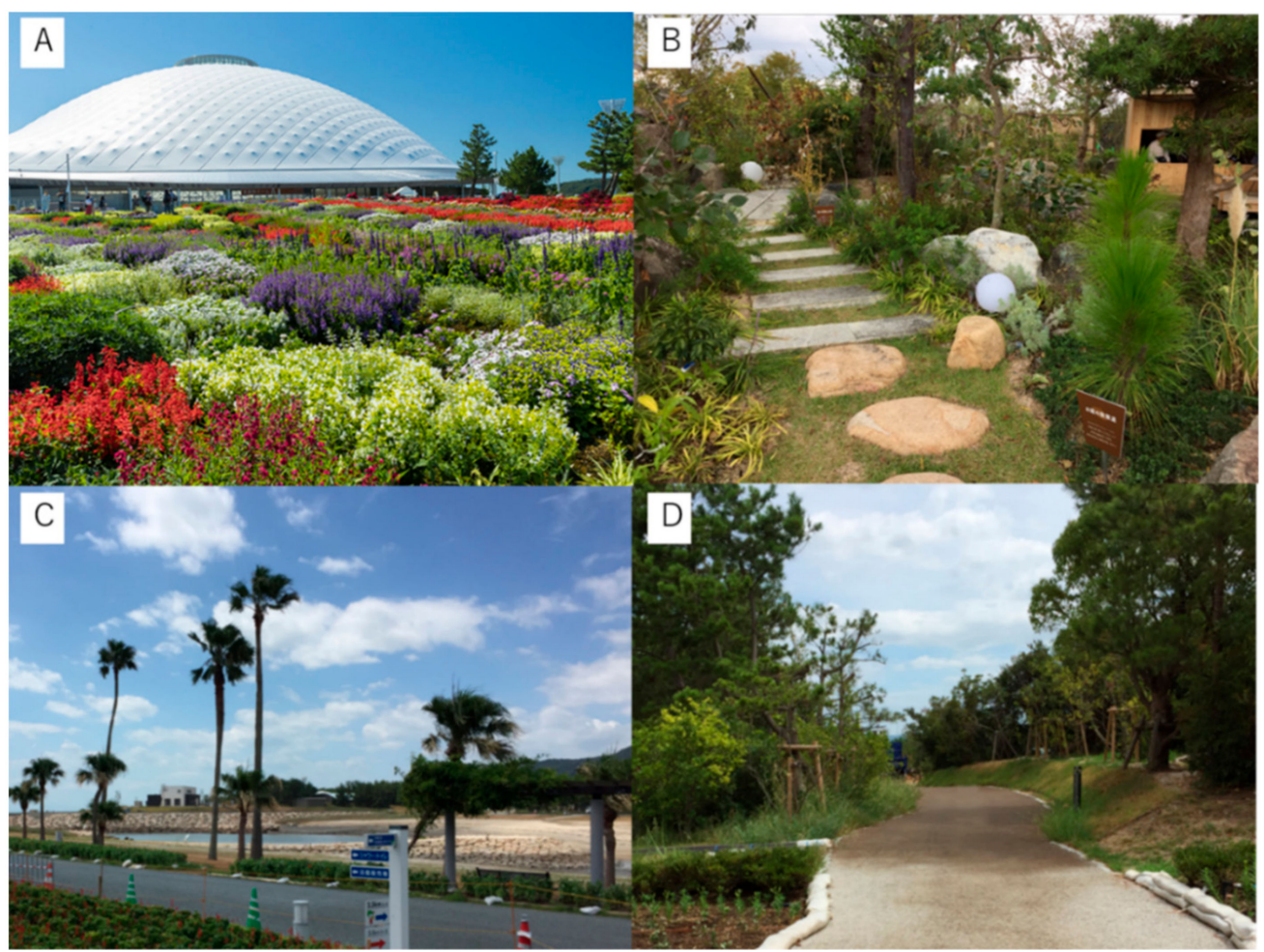

Figure 2. (A): Image of flower area, (B): Image of Garden for Health, (C): Image of ocean area, (D): Image of forest area. 
The collected R-R interval variation from each $R$ peak time was analyzed using Mem Calc/Win (GMS Co., Ltd., Tokyo, Japan) with frequency analysis performed with the maximum entropy method (MEM). Consequently, HRV indicators were automatically calculated regarding the power levels of the high-frequency zone (HF: $0.15 \mathrm{~Hz}-0.40 \mathrm{~Hz}$ ) and the low-frequency zone (LF: $0.04 \mathrm{~Hz}-0.15 \mathrm{~Hz}$ ). HF power indicates parasympathetic nervous activity, and the LF/HF power ratio indicates the balance between the sympathetic and parasympathetic systems [28]. Hitachi Systems Co. Ltd. uses a standard $\mathrm{LF} / \mathrm{HF}$ power ratio of $0.8 \mathrm{~Hz}-2.0 \mathrm{~Hz}$; values below $0.8 \mathrm{~Hz}$ are considered a hyper-sympathetic state and values above $2.0 \mathrm{~Hz}$ are considered a sympathetic state. The ccvTP corrected the sum of LF and HF by heartrate and was used as an index of the magnitude of the total autonomic nervous system's activity. The ccvTP was also used as a reference value in this study because it is automatically analyzed by the Fatigue Measurement Device VM302 to produce autonomic activity.

\subsubsection{Experimental Procedure}

The experiment was conducted at the Yamaguchi Flower Expo between 9 AM and 11 AM in October 2018. This study was a pretest post-test quasi-experiment. All participants were asked to abstain from alcohol consumption inoculation $12 \mathrm{~h}$ before the measurement and from food eating and caffeine consumption $1 \mathrm{~h}$ before. In the pretest before the walk, all the participants' autonomic nervous functions were recorded in the sitting position in the Garden of Health using the Fatigue Measurement Device VM302 to set the starting point and baseline of the experiment. The procedure was identical to the procedure performed during the preliminary survey. Then, all the participants were fitted with the Holter ECG RAC-2512 (Nihon Koden, Tokyo, Japan) to continuously record HRV during the experiment. All the ECG data were directly transmitted to a computer as R-R intervals via the Holter ECG software. The excerpts of the fatigue stress instrument measured before and after walking were ultra- short term, less than $5 \mathrm{~min}$, while the excerpt on the Holter ECG during walking was short-term, between $30 \mathrm{~min}$ and $1.5 \mathrm{~h}$ [28].

All participants carried GPS loggers that matched ECG data to their locations in the walking circuit, and they were allowed to freely move around the study site. The GPS loggers recorded their locations as longitude and latitude, and the locations were identified as one of the four areas using these data.

To assess the influences of exposure to the four areas, the HRV values were computed and analyzed using maximum entropy method software (Mem Calc, GMS, Tokyo, Japan). The coefficient of variance of the R-R intervals (CVRR: standard deviation of the R-R interval/mean of the R-R interval $\times 100$ ) was calculated to obtain a value representing total $\mathrm{HRV}$ power.

The study site used a circuit designed so that visitors entered at the Garden for Health; walked through the forest, flower, and ocean areas; and reached the end of the circuit at the Garden for health.

Once they completed the circuit and were again in the Garden for Health, each participant's autonomic nervous functions were assessed in the sitting position using a fatigue measurement device, VM302.

Lastly, participants were asked whether they thought the crowd was uncomfortably large and which of the four areas was their favorite area.

\subsection{Data Management and Statistical Analysis}

The mean HRV values of each participant during exposure to each of the four areas were calculated. Paired $t$-tests were performed to compare the pretest to the post-test means.

A one-way repeated measures analysis of variance (ANOVA) test was performed to test differences in the HRV mean values of the four areas and post hoc Tukey Tests were used for the multiple comparisons procedure. The cut-off value of statistical significance on all tests was $p<0.05$. All statistical analyses were performed using JMP Pro 13 (SAS Institute Inc, Charlotte, NC, USA). 


\section{Results}

The participants' information and characteristics are presented in Table 1 . The pretest data indicated that approximately $39 \%(n=15)$ of the participants reported allergic rhinitis, $13 \%(n=5)$ reported sleep disorders, and approximately about $29 \%(n=11)$ reported regular physical exercise.

Table 1. Participants' descriptive statistics $(n=38)$.

\begin{tabular}{cccc}
\hline \multirow{2}{*}{ Variable } & Males $(\boldsymbol{n = 1 3 )}$ & Females $(\boldsymbol{n}=\mathbf{2 5})$ & All $(\boldsymbol{n}=\mathbf{3 8})$ \\
\cline { 2 - 4 } & Mean (SD) & Mean (SD) & Mean (SD) \\
\hline Age (years) & $21.9(1.0)$ & $21.2(1.2)$ & \\
Height $(\mathrm{cm})$ & $170.2(6.8)$ & $158.2(5.3)$ & \\
Weight $(\mathrm{kg})$ & $62.0(8.0)$ & $49.8(6.0)$ & \\
BMI $\left(\mathrm{kg} / \mathrm{m}^{2}\right)$ & $21.2(1.9)$ & $19.9(2.2)$ & \\
\hline Physical symptom & Males $(\boldsymbol{n}=\mathbf{1 3})$ & Females $(\boldsymbol{n}=\mathbf{2 5 )}$ & All $(\boldsymbol{n}=\mathbf{3 8})$ \\
& $\boldsymbol{n} \mathbf{( \% )}$ & $\boldsymbol{n}(\boldsymbol{\%})$ & $\boldsymbol{n} \mathbf{( \% )}$ \\
\hline allergic rhinitis & $3(23)$ & $12(48)$ & $15(39)$ \\
sleep disorder & $2(15)$ & $3(12)$ & $5(13)$ \\
fitness habits & $3(23)$ & $8(32)$ & $11(29)$ \\
\hline
\end{tabular}

BMI: Body Mass Index.

\subsection{Baseline HRV}

First, independent samples $t$-tests were used to compare mean HRV scores between those who reported and those who did not report allergic rhinitis, sleep disorder, or regular physical exercise.

Table 2 indicates a significantly lower HF among those who regularly engage in physical exercise than those who do not, and their LF/HF and heartrate were significantly lower than those without regular physical exercise. Most of those who practiced regular physical activity were in the normal range as assumed by the equipment manufacturer. The mean LF/HF of those with sleep disorders was significantly higher than those without a disorder, and most of with sleep disorders were above normal range. Mean HF among those with allergic rhinitis was higher than that of those without it, suggesting that allergic rhinitis might enhance parasympathetic nervous activity, although the difference was not statistically significant.

Table 2. Baseline heartrate variability data in the overall sample and by health condition; statistical significance is of participant $t$-test results $(n=38)$.

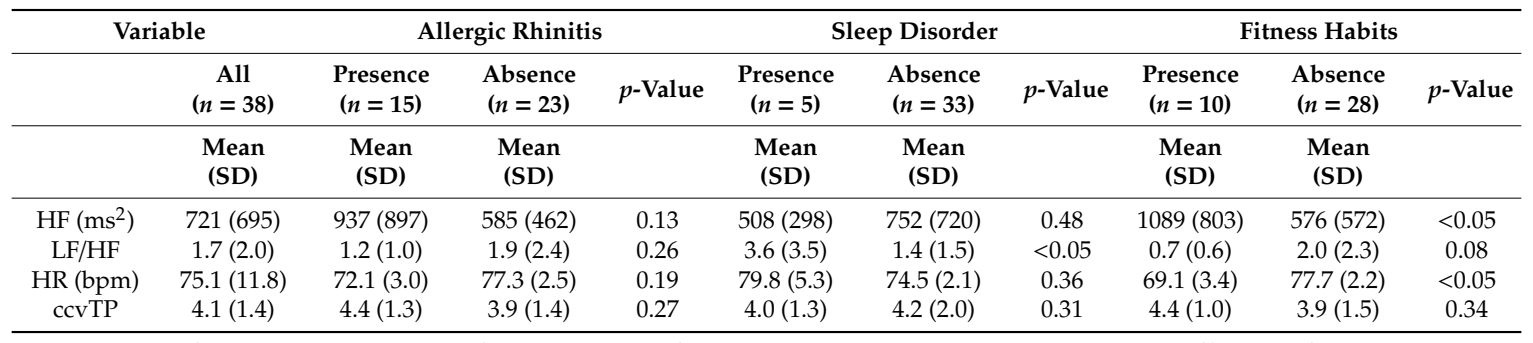

HF: high frequency; LF/HF: low frequency/high frequency ratio; HR: heart rate; ccvTP: coefficient of component variance total power.

\subsection{HRV Change after the Walk}

The HVR was significantly different after the walk only regarding LF/HF ( $p=0.08$ ) (Table 3). 
Table 3. Mean heart rate variability values pretest and post-test $(n=38)$.

\begin{tabular}{cccc}
\hline Variable & Pretest & Post-Test & $p$-Value \\
\hline & Mean (SD) & Mean (SD) & \\
\hline HF $\left(\mathrm{ms}^{2}\right)$ & $557(619)$ & $451(619)$ & 0.20 \\
LF $/ \mathrm{HF}$ & $3.4(4.9)$ & $3.3(3.4)$ & 0.08 \\
HR (bpm) & $75.7(10.1)$ & $76.1(9.2)$ & 0.84 \\
ccvTP & $4.2(1.5)$ & $3.8(1.5)$ & 0.58 \\
\hline
\end{tabular}

HF: high frequency; LF/HF: low frequency/high frequency ratio, HR: heart rate; ccvTP: coefficient of component variance total power.

\subsection{HRV Changes in Four Areas (Forest, Flower, Ocean, and Garden of Health)}

Neither the HF nor the LF/HF was significantly different after the walk, but CVRR tended to be lower in all areas compared to before the walk. The amount of time spent in each area ranged from 2-60 min (Table 4). In particular, LF/HF after spending more than $10 \mathrm{~min}$ in the Garden of Health $(n=16$, mean $=1.7 \pm 1.9)$ was significantly lower than among those who spent less than 10 min there $(n=20$, mean $=4.1 \pm 4.0, p=0.04)$.

Table 4. Mean HRV by environmental area.

\begin{tabular}{ccccccc}
\hline Variable & Garden for Health & Ccean & Flowers & Forest & \multicolumn{2}{c}{ ANOVA } \\
\hline & Mean (SD) & Mean (SD) & Mean (SD) & Mean (SD) & F-Value & $p$-Value \\
\hline HF $\left(\mathrm{ms}^{2}\right)$ & $145(130)$ & $125(109)$ & $125(109)$ & $123(104)$ & 0.31 & 0.81 \\
LF/HF & $6.7(3.7)$ & $6.6(3.5)$ & $6.9(3.5)$ & $6.2(3.0)$ & 0.25 & 0.86 \\
HR (bpm) & $89.4(12.3)$ & $93.4(9.7)$ & $91.4(10.3)$ & $93.1(12.5)$ & 0.91 & 0.44 \\
CVRR & $5.0(1.5)$ & $5.0(1.1)$ & $5.0(1.3)$ & $4.8(1.4)$ & 0.32 & 0.81 \\
$\log$ in time (min) & $3-35$ & $2-14$ & $7-28$ & $8-60$ & & \\
\hline
\end{tabular}

HF: high frequency; LF/HF: low frequency/high frequency ratio; HR: heart rate; CVRR: coefficient of variation R-R interval.

The participants' HRV differences after the walk by condition (allergic rhinitis, sleep disorder, physical exercise) are shown in Table 5.

Table 5. Mean pretest and post-test heart rate variation by condition, allergic rhinitis, sleep disorder and fitness habits.

\begin{tabular}{|c|c|c|c|c|c|c|c|c|c|c|}
\hline \multirow[t]{2}{*}{ Variable } & & \multicolumn{3}{|c|}{ Allergic Rhinitis } & \multicolumn{3}{|c|}{ Sleep Disoder } & \multicolumn{3}{|c|}{ Fitness Habits } \\
\hline & & $\begin{array}{c}\text { Presence } \\
(n=15)\end{array}$ & $\begin{array}{l}\text { Absence } \\
(n=23)\end{array}$ & $p$-Value & $\begin{array}{c}\text { Presence } \\
(n=5)\end{array}$ & $\begin{array}{c}\text { Absence } \\
(n=33)\end{array}$ & $p$-Value & $\begin{array}{l}\text { Presence } \\
(n=10)\end{array}$ & $\begin{array}{l}\text { Absence } \\
(n=28)\end{array}$ & $p$-Value \\
\hline \multirow{2}{*}{$\mathrm{HF}\left(\mathrm{ms}^{2}\right)$} & pretest & $896(835)$ & $510(898)$ & 0.18 & 309 (396) & $710(152)$ & 0.35 & $\begin{array}{c}1184 \\
(1210)\end{array}$ & $452(633)$ & $<0.05$ \\
\hline & post-test & $770(895)$ & $293(309)$ & $<0.05$ & 445 (395) & $481(672)$ & 0.91 & $1099(983)$ & $232(186)$ & $<0.0001$ \\
\hline \multirow{2}{*}{$\mathrm{LF} / \mathrm{HF}$} & pretest & $2.2(3.1)$ & $4.1(5.7)$ & 0.24 & $9.5(10.3)$ & $2.5(3.0)$ & $<0.01$ & $2.1(1.5)$ & $3.8(0.9)$ & 0.34 \\
\hline & post-test & $2.5(3.2)$ & $3.6(3.6)$ & 0.33 & $5.0(3.2)$ & $3.0(3.4)$ & 0.21 & $2.4(3.4)$ & $3.5(3.5)$ & 0.39 \\
\hline \multirow{2}{*}{ HR (bpm) } & pretest & $71.9(8.0)$ & $78.1(10.7)$ & 0.06 & $84.8(6.1)$ & $74.4(9.9)$ & $<0.05$ & $69.5(8.3)$ & $78.1(9.8)$ & $<0.05$ \\
\hline & post-test & $72.7(7.8)$ & $78.3(9.6)$ & 0.07 & $80.9(7.0)$ & $75.4(9.4)$ & 0.22 & $68.8(7.3)$ & $79.0(8.4)$ & $<0.001$ \\
\hline \multirow{2}{*}{ ccvTP } & pretest & $4.7(0.5)$ & $4.1(0.4)$ & 0.35 & $4.7(0.9)$ & $4.3(0.3)$ & 0.66 & $5.3(2.4)$ & $4.0(1.5)$ & $<0.05$ \\
\hline & post-test & $4.2(1.7)$ & $3.7(1.4)$ & 0.29 & $5.0(1.8)$ & $3.7(1.5)$ & 0.08 & $5.1(1.5)$ & $3.4(1.3)$ & $<0.01$ \\
\hline
\end{tabular}

HF: high frequency; LF/HF: low frequency/high frequency rati; HR: heart rate; ccvTP: coefficient of component variance total power.

HF in 10 of the 15 participants who reported allergic rhinitis was lower after the walk.

$\mathrm{LF} / \mathrm{HF}$ in among those who did not regularly exercise, which were often increased, tended to decrease and improve after walking. 


\subsection{Changes in LF/HF after the Walk}

Figure 3 indicates that the participants with low LF/HF scores (below the reference range of 0.8-2.0) had significantly higher LF/HF scores after the walk and higher sympathetic nervous activity. In contrast, $73 \%$ of the 15 participants with high LF/HF in the pretest had lower LF/HF after the walk and a tendency toward reduced sympathetic hyperactivity.

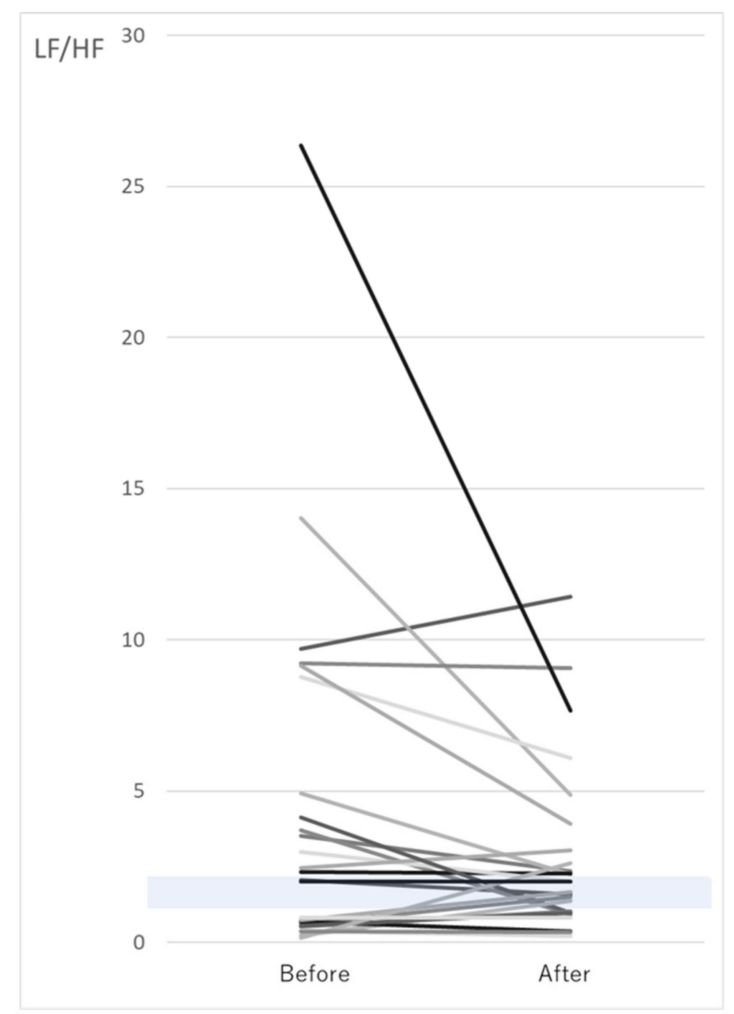

Figure 3. Changes in LF/HF; the gray zone indicates the LF/HF reference range of 0.8-2.0. Different colored lines indicate individual subjects.

LF/HF scores higher than 2.0 were lower after the walk $(n=15, p=0.13)$, whereas LF/HF scores less than 0.8 were significantly higher after the walk $(n=9, p<0.05)$.

\section{Discussion}

Several systematic reviews have indicated that natural environments, such as forests, influenced physical health and relaxation. In medicine, flowers in hospital rooms might reduce patients' pain and stress. Rooftop gardens built at hospitals aim to promote patients' psychological recovery by providing comfort. However, there are no studies comparing the physiological effects among types of environments, such as artificial gardens, forest, ocean, and flower settings.

The Yamaguchi Flower Expo was selected as the experimental site because it had a Garden of Health designed for hospitals along with forest, flower, and ocean areas.

This study aimed to assess the effects of exposure to an artificial garden on the autonomic nervous system's activity by comparing its effects to those of the other natural environments at the Expo.

Sympathetic and parasympathetic nervous system activity was measured using HRV.

The HF, heartrate, and ccvTP values were not significantly different after the walk, but the LF/HF was significantly lower than before the walk, suggesting that exposure to the natural surroundings might have had a suppressing influence on sympathetic nervous activity. Nearly one-quarter $(n=3$, $23 \%)$ of the men and almost one-half $(n=12,47 \%)$ of the women indicated that they had allergic rhinitis. Some previous studies found that allergic rhinitis sufferers were predisposed to parasympathetic 
nervous activity $[29,30]$, many of which found that parasympathetic nervous activity among allergic rhinitis sufferers was suppressed by walking, resulting in an improved balance in autonomic nervous activity.

The present study supports these findings because the participants without allergic rhinitis had significantly lower HF after the walk (510 and 293, respectively, $p<0.05)$, but the effect was not significant for those with allergic rhinitis.

Most of the participants with sleep disorders $(n=5)$ were markedly hyper sympathetic, and the $\mathrm{LF} / \mathrm{HF}$ power ratio indicated that balance between the sympathetic and parasympathetic activity tended toward sympathetic nervous activity. The LF/HF and the heartrate were significantly higher after the walk $(p<0.05)$ among those without a sleep disorder $(n=33)$, suggesting that the walk increased parasympathetic nervous activity and improved the balance between the sympathetic and parasympathetic activity. Those with low LF/HF before the walk had higher LF/HF after the walk, indicating improved sympathetic activity, whereas those with high LF/HF before the walk had lower $\mathrm{LF} / \mathrm{HF}$ after the walk, indicating reduced sympathetic hyperactivity. These findings suggest that walking influenced and regulated the balance of the autonomic nervous activity.

The CVRR was used to measure total HRV power.

The differences after the walk were not statistically significant, but both measures were higher before than after the walk, and they gradually declined during the walk. The participants who reported that they were not physically active $(n=28)$ had significantly lower HF and ccvTP after the walk and a significantly higher heartrate after the walk, but the changes in HRV were non-significant among those who reported physical activity $(n=10)$. These findings suggest that fatigue after a 30-60 min walk might reduce autonomic nervous activity and more strongly influence people who do not regularly engage in physical exercise.

\section{Conclusions}

In this study, the participants were exposed to four types of nature (artificial garden, forest, flowers, and ocean), and no significant differences were found in their effects on the autonomic nervous system. These findings suggest that artificial gardens for health promotion have the same influence as the forest [15], flower [18], and ocean [16], all of which were previously found to have positive effects (e.g., relaxation) on the autonomic nervous system.

Additionally, more than $10 \mathrm{~min}$ of exposure to an artificial garden might be more effective than less exposure. Hospital gardens might enhance their effectiveness for patients' psychological health by providing tools inpatients can use to extend their stays there.

However, this study has some limitations. A major limitation was that the site of the experiment was the Expo site with an artificial garden, which would be difficult to reproduce. The participants were young university students, but many of the patients who use hospital gardens are middle-aged or older, so this experiment should be replicated on samples of older individuals. The effects of variation in the ambient temperature on the autonomic nervous system could not be assessed because the experiment was conducted only during the summer. Depending on the free walk, the walking route and time differed by individual. The differences in the time spent in each area varied because the participants controlled the walk, and the temporal differences among the areas might have influenced the results; however, this study did not test those differences.

Lastly, the large number of visitors at the study site might have congregated as crowds of people that excited the participants in ways that influenced their results. Despite these caveats, this study found that exposure to the Garden of Health and the other natural areas had a beneficial influence on balancing the autonomic nervous systems of healthy young adults.

Author Contributions: Conceptualization, H.S.; methodology, H.S.; formal analysis, H.S. and K.M.; investigation, H.S., K.M., N.M. and S.N.; data curation, H.S. and K.M.; writing—original draft; preparation, H.S.; writing一review and editing, H.S., M.T. and H.N.; visualization, H.S.; supervision, H.S.; project administration; H.S. and M.T., funding acquisition, M.T. All authors have read and agreed to the published version of the manuscript. 
Funding: This work was supported by JSPS KAKENHI Grant Number JP17K12398.

Acknowledgments: The authors would like to express their sincere thanks to the subjects who participated in this study. This study was made possible by the time they spent and completed the walk.

Conflicts of Interest: The authors declare no conflict of interest.

\section{References}

1. The WHO World Mental Health Survey Consortium. Prevalence, Severity, and Unmet Need for Treatment of Mental Disorders in the World Health Organization World Mental Health Surveys. JAMA 2004, 291, 2581-2590. [CrossRef] [PubMed]

2. Dye, C. Health and Urban Living. Science 2008, 319, 766-769. [CrossRef] [PubMed]

3. Wagner, K.H.; Brath, H. A global view on the development of non communicable diseases. Prev. Med. 2012, 54, S38-S41. [CrossRef] [PubMed]

4. Tsuko Tanaka, A.; Takano, T.; Nakam Ura, K.; Takeuchi, S. Health levels infuenced by urban residential conditions in a Megacity Tokyo. Urban Stud. 1996, 33, 879-894. [CrossRef]

5. Peen, J.; Schoevers, R.A.; Beekman, A.T.; Dekker, J. The current status of urban-rural differences in psychiatric disorders. Acta Psychiatr. Scand. 2010, 121, 84-93. [CrossRef] [PubMed]

6. Lederbogen, F.; Kirsch, P.; Haddad, L.; Streit, F.; Tost, H.; Schuch, P.; Wüst, S.; Pruessner, J.C.; Rietschel, M.; Deuschle, M.; et al. City living and urban upbringing affect neural social stress processing in humans. Nature 2011, 474, 498-501. [CrossRef]

7. McKenzie, K.; Murray, A.; Booth, T. The impact of urban-rural environments on mental health Do urban environments increase the risk of anxiety, depression and psychosis? An epidemiological study. Karen McKenzie, Department of Clinical Psychology, University of Edinburgh. Aja Murray an. J. Affect. Disord. 2013, 150, 1019-1024. [CrossRef]

8. Hartig, T.; Mitchell, R.; De Vries, S.; Frumkin, H. Nature and Health. Annu. Rev. Public Health 2014, 35, 207-228. [CrossRef]

9. Ulrich, R.S. Visual landscapes and psychological well-being. Landsc. Res. 1979, 4, 17-23. [CrossRef]

10. Maas, J.; Verheij, R.A.; Groenewegen, P.P.; De Vries, S.; Spreeuwenberg, P. Green space, urbanity, and health: How strong is the relation? J. Epidemiol. Community Health 2006, 60, 587-592. [CrossRef]

11. Im, S.G.; Choi, H.; Jeon, Y.H.; Song, M.K.; Kim, W.; Woo, J.M. Comparison of Effect of Two-Hour Exposure to Forest and Urban Environments on Cytokine, Anti-Oxidant, and Stress Levels in Young Adults. Int. J. Environ. Res. Public Health 2016, 13, 625. [CrossRef] [PubMed]

12. Park, B.J.; Tsunetsugu, Y.; Kasetani, T.; Hirano, H.; Kagawa, T.; Sato, M.; Miyazaki, Y. Physiological Effects of Shinrin-yoku (Taking in the Atmosphere of the Forest)—Using Salivary Cortisol and Cerebral Activity as Indicators-. J. Physiol. Anthr. 2007, 26, 123-128. [CrossRef]

13. Han, J.W.; Choi, H.; Jeon, Y.H.; Yoon, C.H.; Woo, J.M.; Kim, W. The Effects of Forest Therapy on Coping with Chronic Widespread Pain: Physiological and Psychological Differences between Participants in a Forest Therapy Program and a Control Group. Int. J. Environ. Res. Public Health 2016, 13, 255. [CrossRef] [PubMed]

14. Joung, D.; Kim, G.; Choi, Y.; Lim, H.; Park, S.; Woo, J.M.; Park, B.J. The Prefrontal Cortex Activity and Psychological Effects of Viewing Forest Landscapes in Autumn Season. Int. J. Environ. Res. Public Health 2015, 12, 7235. [CrossRef] [PubMed]

15. Horiuchi, M.; Endo, J.; Takayama, N.; Murase, K.; Nishiyama, N.; Saito, H.; Fujiwara, A. Impact of Viewing vs. Not Viewing a Real Forest on Physiological and Psychological Responses in the Same Setting. Int. J. Environ. Res. Public Health 2014, 11, 10883-10901. [CrossRef] [PubMed]

16. Tsutsumi, M.; Nogaki, H.; Shimizu, Y.; Stone, T.E.; Kobayashi, T. Individual reactions to viewing preferred video representations of the natural environment: A comparison of mental and physical reactions. Jpn. J. Nurs. Sci. 2017, 14, 3-12. [CrossRef]

17. Triguero-Mas, M.; Dadvand, P.; Cirach, M.; Martínez, D.; Medina, A.; Mompart, A.; Basagaña, X.; Gražulevičienè, R.; Nieuwenhuijsen, M.J. Natural outdoor environments and mental and physical health: Relationships and mechanisms. Environ. Int. 2015, 77, 35-41. [CrossRef]

18. Ikei, H.; Komatsu, M.; Song, C.; Himoro, E.; Miyazaki, Y. The physiological and psychological relaxing effects of viewing rose flowers in office workers. J. Physiol. Anthr. 2014, 33, 1-5. [CrossRef] 
19. Li, Q.; Kobayashi, M.; Wakayama, Y.; Inagaki, H.; Katsumata, M.; Hirata, Y.; Hirata, K.; Shimizu, T.; Kawada, T.; Ohira, J.T.; et al. Effect of Phytoncide from Trees on Human Natural Killer Cell Function. Int. J. Immunopathol. Pharmacol. 2009, 22, 951-959. [CrossRef]

20. Song, C.; Ikei, H.; Miyazaki, Y. Physiological Effects of Visual Stimulation with Forest Imagery. Int. J. Environ. Res. Public Health 2018, 15, 213. [CrossRef]

21. Song, C.; Ikei, H.; Kagawa, T.; Miyazaki, Y. Physiological and Psychological Effects of Viewing Forests on Young Women. Forests 2019, 10, 635. [CrossRef]

22. Roe, J.; Barnes, L.; Napoli, N.; Thibodeaux, J. The Restorative Health Benefits of a Tactical Urban Intervention: An Urban Waterfront Study. Front. Built Environ. 2019, 5, 1-10. [CrossRef]

23. Vert, C.; Gascon, M.; Ranzani, O.; Márquez, S.; Triguero-Mas, M.; Carrasco-Turigas, G.; Arjona, L.; Koch, S.; Llopis, M.; Donaire-Gonzalez, D.; et al. Physical and mental health effects of repeated short walks in a blue space environment: A randomised crossover study. Environ. Res. 2020, 188, 109812. [CrossRef] [PubMed]

24. Gascon, M.; Zijlema, W.; Vert, C.; White, M.P.; Nieuwenhuijsen, M.J. Outdoor blue spaces, human health and well-being: A systematic review of quantitative studies. Int. J. Hyg. Environ. Health 2017, 220, 1207-1221. [CrossRef]

25. Lahart, I.; Darcy, P.; Gidlow, C.; Calogiuri, G. The effects of green exercise on physical and mental wellbeing: A systematic review. Int. J. Environ. Res. Public Health 2019, 16, 1352. [CrossRef]

26. Song, C.; Ikei, H.; Kagawa, T.; Miyazaki, Y. Effects of Walking in a Forest on Young Women. Int. J. Environ. Res. Public Health 2019, 16, 229. [CrossRef]

27. De Brito, J.N.; Pope, Z.; Mitchell, N.; Schneider, I.E.; Larson, J.M.; Horton, T.H.; Pereira, M.A. The effect of green walking on heart rate variability: A pilot crossover study. Environ. Res. 2020, 185. Available online: https://www.sciencedirect.com/science/article/pii/S0013935120303017 (accessed on 18 March 2020). [CrossRef]

28. Massaro, S.; Pecchia, L. Heart Rate Variability (HRV) Analysis: A Methodology for Organizational Neuroscience. Organ. Res. Methods 2019, 22, 354-393. [CrossRef]

29. Lal, D.; Corey, J.P. Vasomotor rhinitis update. Curr. Opin. Otolaryngol. Head Neck Surg. 2004, 12, $243-247$. [CrossRef]

30. Vayisoglu, Y.; Ozcan, C.; Pekdemir, H.; Gorur, K.; Pata, Y.S.; Çamsarı, A. Autonomic Nervous System Evaluation Using Heart Rate Variability Parameters in Vasomotor Rhinitis Patients. Int. J. Otolaryngol. 2006, 35, 338-342. [CrossRef]

Publisher's Note: MDPI stays neutral with regard to jurisdictional claims in published maps and institutional affiliations.

(C) 2020 by the authors. Licensee MDPI, Basel, Switzerland. This article is an open access article distributed under the terms and conditions of the Creative Commons Attribution (CC BY) license (http://creativecommons.org/licenses/by/4.0/). 